\title{
Interrogating Place: A Socio-Sensory Approach
}

\author{
Kelum Palipane \\ Melbourne School of Design, Melbourne, Australia
}

\begin{abstract}
Many cities in emerging nations caught up in the global process of urban regeneration pursue a western model of modernity and urbanity without much consideration for its impact on social sustainability. This can result in entrenching already inequitable conditions where policies typically address the interests of elite minorities. This paper presents an alternative approach to analysing and engaging with place and its sociality to reveal nuanced place making practices of existing communities giving voice to marginalized groups and views. Presented within the context of fieldwork studies in the Melbourne suburb of Footscray, this paper focuses on a place mapping technique based on sensory ethnography to identify and analyse existing spatial practices of communities. Ethnographic data is supplemented by audio and visual recordings which are then synthesized and represented in a series of multimodal diagrams based the concept of vertical montage which explores the relationships between time, space and activity. This paper also briefly presents a design exploration of a Master of Architecture student at the University of Melbourne who adopted the mapping technique, developing a richly experiential and programmatically appropriate design for urban regeneration. The methods presented in this paper may help inform the development of regional model of 'modernity' that is socially sustainable and specific to place. One that attempts to address inequity in the participation process and acknowledges the importance of existing spatial practices in creating complex and pluralistic urban spaces.
\end{abstract}

Keywords: social equity, urban regeneration, sensory ethnography, embodied activity, multimodal mapping

\section{Introduction}

Many cities, urban centres and inner city suburbs around the world are currently undergoing urban regeneration. While different reasons drive these transformations of urbanity, in many emerging nations it is often inextricably tied with goals towards modernisation. Modernity for many developing nations is a utopian concept, difficult to imagine outside the idealized conditions of the west. Inevitably, this leads to the uncritical adoption of western policies and methods, often applied in a top-down manner by powerful decision makers - negatively impacting the populations on the ground. While the drive for urban regeneration may differ considerably between this and what is occurring in the inner city suburbs of Melbourne which this paper focuses on, it is possible to draw parallels between the impacts on social equity that occurs within marginalised communities in both contexts.

Regenerated areas can often be characterised by a lack plurality in not only spatio-aesthetics but also in demographic make-up and activity. Methods and policies often overlook nuanced and layered place making practices of the local communities. In addition to this, within a consumer society such as Australia these places often become commodified spaces available for consumption, compounding issues of social equity by its marginalisation of certain groups. By means of an exploratory process which includes investigation through design, this study examines how this inequity can be addressed by designers through the consideration of the socially produced sensory realm generated by existing spatial practices. 
This study is conducted in Footscray; a suburb located 5km west of central Melbourne. With a population of around 13000 and land area of 5 square kilometres it is one of the oldest suburbs of Melbourne (Profile.id, 2015). ${ }^{1}$ It is an immigrant receptor area and census data reveals that $40 \%$ of people in Footscray arrived in Australia within 5 years prior to 2011 (Profile.id, 2015). ${ }^{2}$ The diasporic populations brought with them specialty shops, market produce, ethnic cuisines and languages. Social clubs and societies were also set up by the respective ethnic groups giving an indication of a vibrant social culture. These diasporic communities generate distinct and varied sensorial landscapes within the places they inhabit. The sensory embodied activities involving sights, sounds, tastes and smells are used to recreate a culturally familiar 'place' within a larger mostly alien landscape. The resulting socially produced sensorial regime generated by cultural behaviours is not necessarily measured by economic productivity or generalisable for the market.

Maree Pardy argues that during urban regeneration, in such culturally diverse environments, this diversity is used as a marketable commodity through which to sell the image of cities or town centres. It has been further observed that the activities of certain groups are hidden or removed during revitalisation if they are not perceived as adding value to this marketable 'image' of diversity (Pardy, 2009). ${ }^{3}$ This usually entails the suppression and control of the sensorial; inextricably entwined with day to day dwelling practices, often perceived as offensive, disorderly, subversive, and antagonistic, but potentially giving voice to the marginalised. This entrepreneurial approach to regeneration in which localities attempt to market for competition on a global stage, ultimately produces sensorially 'safe' environments that are non-confronting, de-politicised, and suited for mainstream consumption.

Monica Degen stresses the importance of the senses and sensory embodied activity in informing the concept of 'place', writing that it "......draws attention to the importance of the sensuous geography of place informing our experience of 'dwelling in public' (Degen 2008). ${ }^{4}$ The sensory landscape creates embodied emotional ties and points of attachment between ourselves and the physical environment" (Degen, 2008). ${ }^{5}$ Within architectural discourse most existing works both theoretical and practical that explore the role of the senses - particularly through the influence of phenomenology - primarily construct an 'essentialist' viewpoint, where a generic body, absent of cultural, age and gender specificities is considered. It is also a passive body where engagement with the environment is limited to experiencing the 'delight' of architecture through the senses.

Other disciplines such as the humanities and social sciences have investigated the significance of local sensory categories in urban place making, how they operate in everyday life and how they interact with the wider political and power configurations; all of which can influence urban fabric. This body of work involving the sociality of the senses seems to exist outside the realm of practice with an apparent lack of structured studies exploring or demonstrating the practical application of such knowledge in the production of urban environments.

This paper presents a method of interrogating site based on a sensory model, where the sensorial become $a$ route to unravelling nuanced place making practices. It is a method that enables designers to grasp the nuances to represent it in a way that retains its complexity and to make use of this knowledge within the parameters of architectural design. The broader aim of this research is to enable architects to produce designs for urban regeneration that reflect the diverse sociality of the existing demography. The

\footnotetext{
${ }^{1}$ Based on 2011 Census data, viewed August, 2014, http://profile.id.com.au.

${ }^{2}$ Profile.id, (2015) Footscray Birthplace, viewed 15 August, 2015, http://profile.id.com.au/maribyrnong/birthplace?WebID=110.

${ }^{3}$ Pardy, M. (2009) 'Multicultural Incarnations: Race, Class and Urban Renewal', in The Future of Sociology: Proceedings of the 2009 Annual Conference of The Australian Sociological Association, Canberra, ACT, 2009.

${ }^{4}$ Degen, M. (2008) Sensing Cities: Regenerating Public life in Barcelona and Manchester, Abingdon: Routledge, pp. 157.

${ }^{5}$ Degen, M. (2008) Sensing Cities, pp. 157.
} 
socio-cultural implications of behaviour in urban settings and design outcomes based on that have been explored, for example by Amos Rapoport and Jan Gehl, (Rapport, 1976, 1977 \& Gehl, 1987, 1996, 2013), ${ }^{6}$ however, this research was approached through the impetus of how architects could contribute to issues of social equity in public spaces while still inhabiting a strategic position within the urban regeneration process.

\section{The Sensorial in Architectural Discourse}

Some of the key theorists and practitioners that have considered the sensorial in the built environment include George Simmel, Christian Norberg-Schulz (via Martin Heidegger), Kevin Lynch, Gordon Cullen, Peter Zumthor, Juhani Pallasmaa and Steven Holl.

The experiential, and thereby sensuous, dimensions of architecture began to be acknowledged with the popularization of phenomenology in architecture. Influenced by the writings of Martin Heidegger, effort was invested into capturing the 'character' of place by engaging site and tectonics. Christian Norberg-Shulz's Genius Loci: Towards a Phenomenology of Architecture was considered seminal in its contribution to this debate. The 1960s and ' 70 s, saw the emergence of a body of work that investigated methodologies in capturing the more experiential dimensions of a city. Most notable were the works of urban theorist Kevin Lynch. Lynch's Image of the City explores the 'imageability' of cities, a method comprising of mapping a category of elements used in the cognitive delineation of the city by consulting many users. The ensuing information is then collated and layered on plans. Lynch stresses that the cognitive mapping is constructed through interpersonal exchange and in doing so, shifts away from a purely phenomenological standpoint (Lynch, 1995). ${ }^{7} \mathrm{He}$ writes, "Cognition is an individual process, but its concepts are social creations (Lynch, 1995)."

From the 1970s onwards a body of work has emerged most notably contributed to by Michel de Certeau and Henri Lefebvre that explores the impact of cultural and spatial practices in the production of urban space. This re-evaluation of the significance of the social body in placemaking inspired investigations into sexuality and gender and how certain urban practices are hierarchised according to this. The work of Elizabeth Grosz explores the specific corporeality of gender through the theorizations of Michel Foucault and Gilles Deleuze amongst others (Grosz 1995). ${ }^{9}$

With the critique of visual culture, the 1990-2000s saw a re-engagement in a phenomenological approach to the experience of architecture led by both theorists and practitioners. Notable within this movement are Juhani Pallasmaa, Steven Holl and Peter Zumthor. Zumthor's primary concern lies in the perception of form, details and materials and he highlights the importance of drawing on his own experiences and memories in creating meaningful architectural experiences. Meanwhile, architect Stephen Holl's work places emphasis on the sensuous experience of architecture. He writes, "The essences of material, smell, texture, temperature, and touch vitalize everyday existence...." (Holl,

\footnotetext{
${ }^{6}$ Rapoport, A. (1976) The Mutual Interaction of People and their Built Environment: A Cross-cultural Perspective, The Hague: Mouton, and Rapoport, A. (1977) Human Aspects of Urban Form: Towards a Man-Environment Approach to Urban Form and Design, Oxford: Pergamon Press.

Jan Gehl has specifically developed quantitative tools that privilege pedestrians in the urban landscape. His body of work has been widely adopted in urban planning processes throughout the world since the 1980s.

Gehl J. \& Birgitte Svarre, B. (2013) How to Study Public Life, Steenhard, K. (Trans.), Washington DC: Island Press. Gehl \& Gemzøe, L. (1996) Public Spaces, Public Life, Copenhagen: Danish Architectural Press and Gehl, J. (1987) Life Between Buildings: Using Public Space, (Trans.), Koch, J. (1987) New York: Van Nostrand Reinhold.

${ }^{7}$ Lynch, K. (1995) City Sense and City Design: Writings and Projects of Kevin Lynch, Banerjee, T. \& Southworth, M. (Eds.), Massachusetts: MIT Press.

${ }^{8}$ Lynch, City Sense and City Design, pp. 233.

${ }^{9}$ Grosz, E. (1995) Space, Time and Perversion: Essays on the Politics of Bodies, Abingdon: Routledge.
} 
2000). ${ }^{10}$ Finnish architect and theoretician Juhani Pallasmaa's body of work centres on the critique of oculacentrism. Pallasmaa analogises art and architecture, writing, "If it lacks contact with the sensory memories that live in our subconscious and link our various senses, art could not but be reduced to mere meaningless ornamentation" (Pallasmaa, 1996). ${ }^{11}$ And in searching to achieve a multi-sensory experience through architecture he highlights three key components in his theoretical writing; hapticity, materiality and 'fragile' architecture. Haptic architecture is described as multi-sensory, where experience is stimulated by all the senses, contributing to situating the observer at the centre of the encounter. Materiality is considered through the narrative of materials, where time and decay become evident and act as temporal metaphors. Finally he describes 'fragile' architecture as, "The architecture of weak image is contextual and responsive... it is concerned with real sensory interaction instead of idealized and conceptual manifestations" (Pallasmaa, 2000). ${ }^{12}$ Although phenomenology in architecture "led to a renewed interest in the sensuous qualities of materials, light, and color, and in the symbolic, tactile significance of the joint...." (Nesbitt,1996), ${ }^{13}$ this approach held limited potential for this study as it dealt with direct experience before reflection and relied heavily on the material properties of external matter and objects. This meant that meaning associated with the sensory was overlooked creating an essentialised view of sensory perception.

More recently, on investigations into urban soundscapes, Rogerson and Rice have highlighted the work of Manon Raimbault and Daniele Dubois who have evaluated the role of soundscapes in urban planning and design (Rogerson \& Rice, 2009). ${ }^{14}$ The process includes noise mapping to identify sound sources and their relationship to urban activities and discerning meaning through various qualitative methods such as surveys and interviews. Raimbault and Dubois make reference to a human centred approach which is a departure from assessing urban environments using a scientific framework of noise control. Further innovative approaches in analysing soundscapes have been developed by sociologist Mags Adams (Adams, M. et al, (2007). ${ }^{15}$ She has been instrumental in the development of a participatory methodology where photo surveys, soundwalks and semi-structured interviews are combined to glean information on resident's perception of urban environments.

These methodologies rely on the reflexive capacities of the participants and their ability to articulate their perceptions. This can be seen as an inherent weakness as much of the uncertainty, nuance and complexity of embodied knowledge is often difficult to articulate through quantitative research or traditional qualitative methods of interviews, focus groups etc.

\section{Methodological Framework}

I argue that by directly observing lived space and its day to day interactions, a situation is created such that information about modes of occupation is not dependent on the ability of the occupants to articulate their views. Sarah Pink provides a methodological approach in which an emplaced and collaborative ethnography is central (Pink, 2008 \& 2009). ${ }^{16}$ The methodology she proposes is a

\footnotetext{
${ }^{10}$ Holl, S. (2000) Parallax, New York: Princeton Architectural Press.

${ }^{11}$ Pallasmaa, J. (1996) 'The Geometry of Feeling: A Look at the Phenomenology of Architecture,' in Theorizing a New Agenda for Architecture An Anthology of Architectural Theory 1965-1995, Nesbitt, K. (Ed.)New York: Princeton Architectural Press. pp. 450.

${ }^{12}$ Pallasmaa, J. (2000) 'Hapticity and Time: Notes on Fragile Architecture,' in RIBA Discourse Lecture, EMAP Architecture. http://iris.nyit.edu/ rcody/Thesis/Readings/Pallasmaa\%20-\%20Hapticity\%20and\%20Time.pdf.

${ }^{13}$ Nesbitt, K. (Ed.) (1996) Theorizing a New Agenda for Architecture: An Anthology of Architectural Theory 1965-1995, New York: Princeton Architectural Press, pp.29.

${ }^{14}$ Rogerson, R. \& Rice, G. (2009) 'Making Sense of Places: 'Moral Geographies' of Sensory Urbanism', Architectural Theory Review, Vol. 14, no. 2, pp. 142-155.

${ }^{15}$ Adams, M. Moore, G. Cox, T. Croxford, B. Refaee, M. \& Sharples, S. (2007) 'The 24-hour City: Residents' Sensorial Experiences', Senses and Society, Vol 1, no. 2, pp. 201-216.

${ }^{16}$ Pink, S. (2008) 'An Urban Tour: The Sensory Sociality of Ethnographic Place-making', Ethnography, Vol. 9, no. 2, pp. 175-196. Pink, S. (2009) Doing Sensory Ethnography, London: Sage Publications Ltd.
} 
specifically sensorial approach to ethnography, using the senses as a route to unravelling people's place making practices.

This study therefore utilizes a variety of ethnographic methods to gather socio-sensory data. Pink asserts that in engaging in sensory ethnography a multimodal approach to collecting and representing the data is critical because of the understanding that sensory perception is itself multimodal with different sensory modes such as sight, sound, taste, touch, smell and kinesthesis interconnecting, overlapping and collaborating in forming sensory knowledge (Pink 2009). ${ }^{17}$ By approaching collection through a variety of methods, I was able to gain varying sources of information through different perceptual modes. The phenomena were recorded through audio-visual multi-media in an attempt to capture and retain its multi-modality.

Sensory rhythms were identified in designated locations and how they fluctuate with time was recorded (Palipane, (2011). ${ }^{18}$ The ethnographic methods used to gather experiential data that supplement the identified sensory rhythms can be categorised into two groups - 'non-participant observation' (Thwaites \& Simkins, 2007) ${ }^{19}$ and 'participant observation' (Pink, 2009) ${ }^{20}$ methods. 'Non-participant' observation involved photographic and video documentation as well as sound recordings to support the evidence of the identified sensescapes. These are visual methods as Pink writes, that "....do not record touch, taste, smell or emotion....However, an understanding of the senses as essentially interconnected suggests how (audio) visual images and recordings can evoke, or invite memories of the multisensoriality of the research encounter" (Pink, 2009). ${ }^{21}$ Behaviour tracing or anthropological tracking was used to investigate traces of behaviour patterns left behind as evidence in the built environment (Thwaites \& Simikins, 2007). ${ }^{22}$ In addition to this, written notes and sketches recorded impressions, insights, and events.

To record the intersectional relationship between time, space and the body, sketches were made that analyzed the built environment relative to the bodies engaged in it. Plans provided an understanding of the density of bodies in space, their orientation towards each other or a structure and their relative positions in space. Sections indicated the relationship between bodies and structures/built environment, how something is touched. It also provided and understanding of the volumetric space and scale relationship to bodies.

My own spatial trajectory within the context was significant for gaining an understanding about the wider context. I noted and recorded movements in a fieldwork journal. Architects and designers see this re-enforcing of the spatial dimension in the methodology as a necessary step if it is to be a fundamental part of a design process that can be adopted.

\section{Multimodal Mapping Diagram}

The data collected during fieldwork included sketches, diary, notes, photos and multimedia such as video and sound recordings. Each medium conveyed knowledge of the socio-sensory phenomena in a

\footnotetext{
${ }^{17}$ Pink, S. (2009) Doing Sensory Ethnography, London: Sage Publications Ltd.

${ }^{18}$ Details on methodology and site selection can be found in the following conference paper by author: Palipane, K. (2011) 'Towards a Sensory Production of Space: Developing a Conceptual Framework of Inquiry based on Socio-sensory Perception', in International Research Committee 21 (RC21) Conference - The Struggle to Belong: Dealing with Diversity in 21st Century Urban Settings, Amsterdam. www.rc21.org/conferences/amsterdam2011/edocs/Session\%201/RT1-1-Palipane.pdf

${ }^{19}$ Thwaites, K. \& Simkins. I. (2007) Experiential Landscape: An Approach to People, Place and Space, Abingdon: Routledge, pp. 83.

${ }^{20}$ Pink, S. (2009) Doing Sensory Ethnography, London: Sage Publications Ltd, pp. 63.

${ }^{21}$ Pink, S. (2009) Doing Sensory Ethnography, London: Sage Publications Ltd, pp. 101

${ }^{22}$ Thwaites, K. \& Simkins. I. (2007) Experiential Landscape: An Approach to People, Place and Space, Abingdon: Routledge, pp.87.
} 
particular way. Sociologist Andrew Sparkes calls for exploration of new methods of representation for sensory ethnography stating that traditional narrative styles used in ethnographic work does not adequately capture the sensory experiences of both the researcher and participants adequately (Sparkes, 2009). ${ }^{23}$ To be a tool to be adopted by architects who work primarily through visual methods it needed to sit easily adjacent to current modes of engagement. It was also necessary for the data to be evocative of the phenomenon as encountered on site allowing others to engage with the data in a critical manner. Mainly, it needed to retain the interconnections between time, space and the social body, reflecting the mode of data collection.

I developed a mapping diagram to address these issues (Figure 1). The structural approach for the mapping diagram was adapted from the film composition process based on 'vertical montage' (Eisenstein, 1991) 24 $^{4}$ utilised by Sergei Eisenstein in his film Alexander Nevsky. Goodwin writes, "The concept of vertical montage is drawn from the notation on an orchestral score, where vertical structure indicates the interrelationship of all the instrumental elements at a particular moment" (Goodwin, 1993). ${ }^{25}$ Adoption of this method allowed me to retain the interrelationship between the different modes of sensory data collected on site by juxtaposing many (multimodal) parts to produce a coherent whole. It also allowed the element of time to be represented. Categories of the multimodal mapping diagram consists of:

INSIGHT- includes diary entries, reflective narratives, quotations from impromptu interviews and conversations as well as embedded sound and video feeds that directly correspond to the sensory rhythms depicted underneath.

BODY AND SPACE- As Degen writes, "Activity rhythms are intricately linked to sensuous rhythms. As public life is punctuated and produced through activities, we experience these though the senses. The unfolding sensory landscape is created through past and present activities" (Degen, 2008). ${ }^{26}$ The embodied activity that is involved in creating these rhythms is represented by photographs and sketches in the body-space segment in map. They also depict corporeal engagement in space giving insight into kinaesthetic involvement with the built environment.

The physicality of a place and how it may impact on its inhabitants is reflected in plan and sectional diagrams where relevant. THE PLAN VIEW- gives an understanding of the density of bodies in space, their orientation towards each other and/or adjacent structures and their relative positions in space.

THE SECTION VIEW- elaborates the relationship between bodies and structures/built environment. How something is touched. The section also provides an understanding of the volumetric space and scale.

My personal spatial journey was responsive to the sensory rhythms that evolved in the site. From the designated spot for rhythmanalysis I moved towards identified sources of the rhythms for closer interrogation, observation and at times, personal corporeal involvement. These spatial trajectories consisting of pauses and movements are depicted in the mapping diagram using the Lund approach to time-geography (Parke \& Thrift, 1980). ${ }^{27}$ This process allows complex traces of movement in space to be

\footnotetext{
${ }^{23}$ Sparkes, A. (2009) 'Ethnography and the Senses: Challenges and Possibilities', Qualitative Research in Sport and Exercise, Vol. 1, no.1, pp. 21-35.

${ }^{24}$ Eisenstein S. (1991) Towards a Theory of Montage: Sergei Eisenstein Selected Work Volume 2, Glenny, M. \& Taylor, R. (Eds.), London: British Film Institute Publishing.

${ }^{25}$ Goodwin, J. (1993) Eisenstein, Cinema and History, Urbana: University of Illinois Press, pp. 175.

${ }^{26}$ Degen, M. (2008) Sensing Cities, pp. 173.

${ }^{27}$ Parkes, D. \& Thrift, N. (1980) Times, Spaces and Places: A Chronogeographic Perspective, New York: John Wiley \& Sons Ltd, pp. 243.
} 
depicted in relation to time (Parkes \& Thrift, 1980). ${ }^{28}$ In the mapping diagram, the timeline remains a universal axis while the spatial context is shown underneath in map format. These two aspects of time and space are then linked by a 'category space' (Parkes \& Thrift, 1980) ${ }^{29}$ dynamic map which gives insight into my spatial trajectory against the timeline.

Reflecting on the overall reading of the mapping diagrams as in Eisenstein's vertical montage, space, time and the corresponding multimodal information are encouraged to be read together as a vertical episode.

${ }^{28}$ Parkes, D. \& Thrift, N. (1980) Times, Spaces and Places: A Chronogeographic Perspective, New York: John Wiley \& Sons Ltd, pp. 243.

${ }^{29}$ Parkes, D. \& Thrift, N. (1980) Times, Spaces and Places: A Chronogeographic Perspective, New York: John Wiley \& Sons Ltd, pp. 243. 

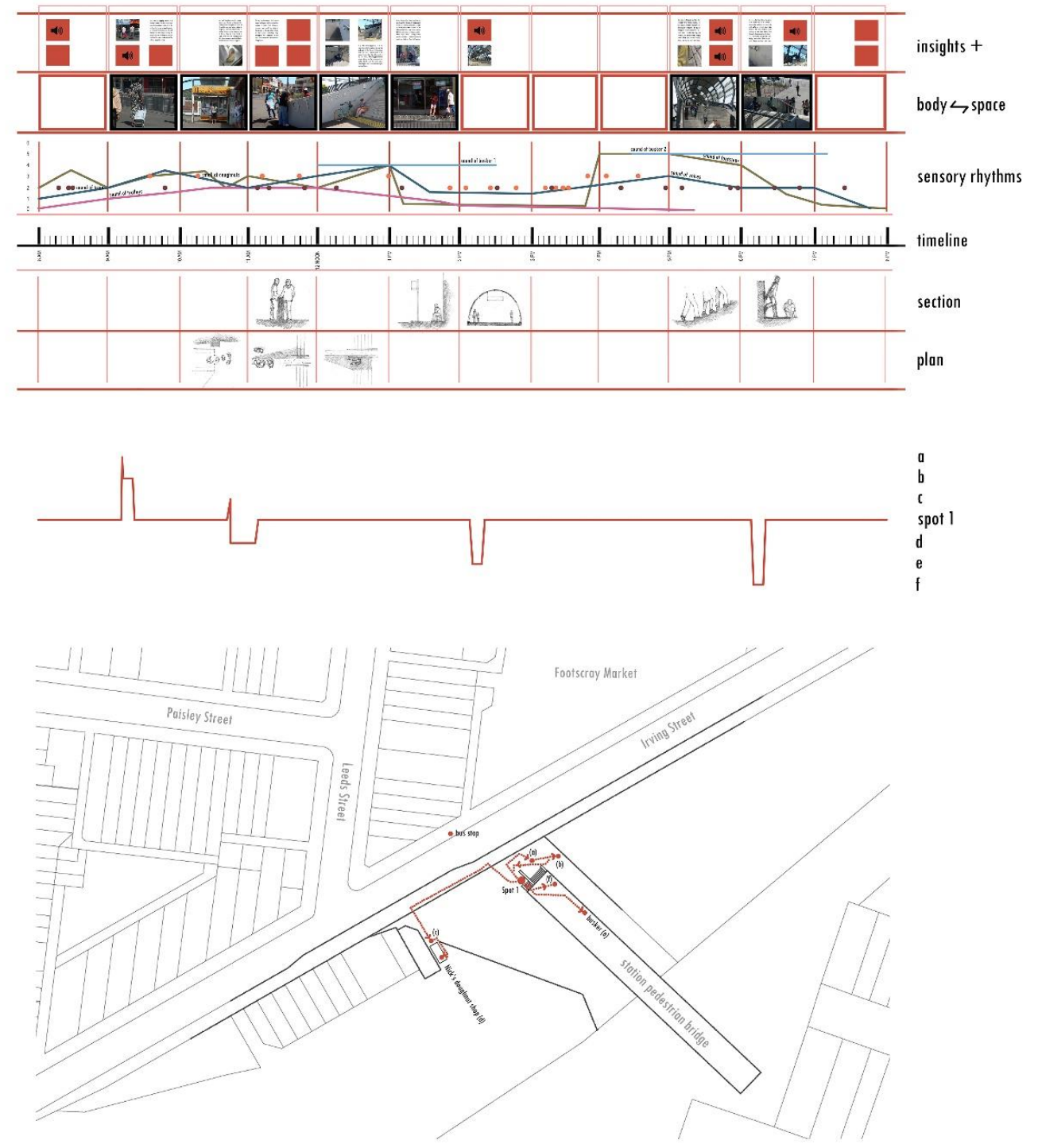

spatial trajectory

\section{path A spot 1}

Fig. 1: Example of multimodal mapping diagram - Path A Spot 1, Oct 2010. Refer link for interactive map: https://www.dropbox.com/s/egyparp7llzfi73/Path\%20A_Spot\%201.pdf?dl=0 


\section{Design Exploration}

One of main aims of this research was to explore how the specific type of knowledge generated by the multimodal mappings can impact architectural thinking. With the aim of expanding scholarship and multiplying outcomes, application in a studio setting was thought to be ideal as it is a space as Donald Schon writes, where practice and reflection can intersect (Schon, 1985). ${ }^{30}$

Students engaged with my own mappings as well as conducting mapping exercises themselves. The multimodal mappings became the basis from which they generated design outcomes for selected urban regeneration projects. It was seen that within the studio there was an emergence of multiplicity; in design concepts, programmes and representation techniques varying quite distinctly from student to student. However, it became evident that this multiplicity took place within a framework of broader themes that were common threads running across the mappings and the design work. In the following pages, I will illustrate this by analysing a single selected episode derived from the mappings of Footscray. The episode is unpacked to reveal socio-spatial markers which form a framework through which the design work is reviewed. These markers are literally 'traced' through the discussions as they emerge, through bold lettering. While the socio-spatial markers that emerged in the themes are traced in the designs, how they impact architectural thinking is evaluated through the parameters of spatiality, programme, scale, materiality and detail:

\begin{tabular}{|l|l|l|l|l|l|l|}
\hline$S P$ & PR & SC & MT & DT \\
\hline
\end{tabular}

${ }^{30}$ Schon, D. (1985) The Design Studio: An Exploration of Its Traditions and Potentials, London: RIBA Publications for RIBA Building Industry Trust. 

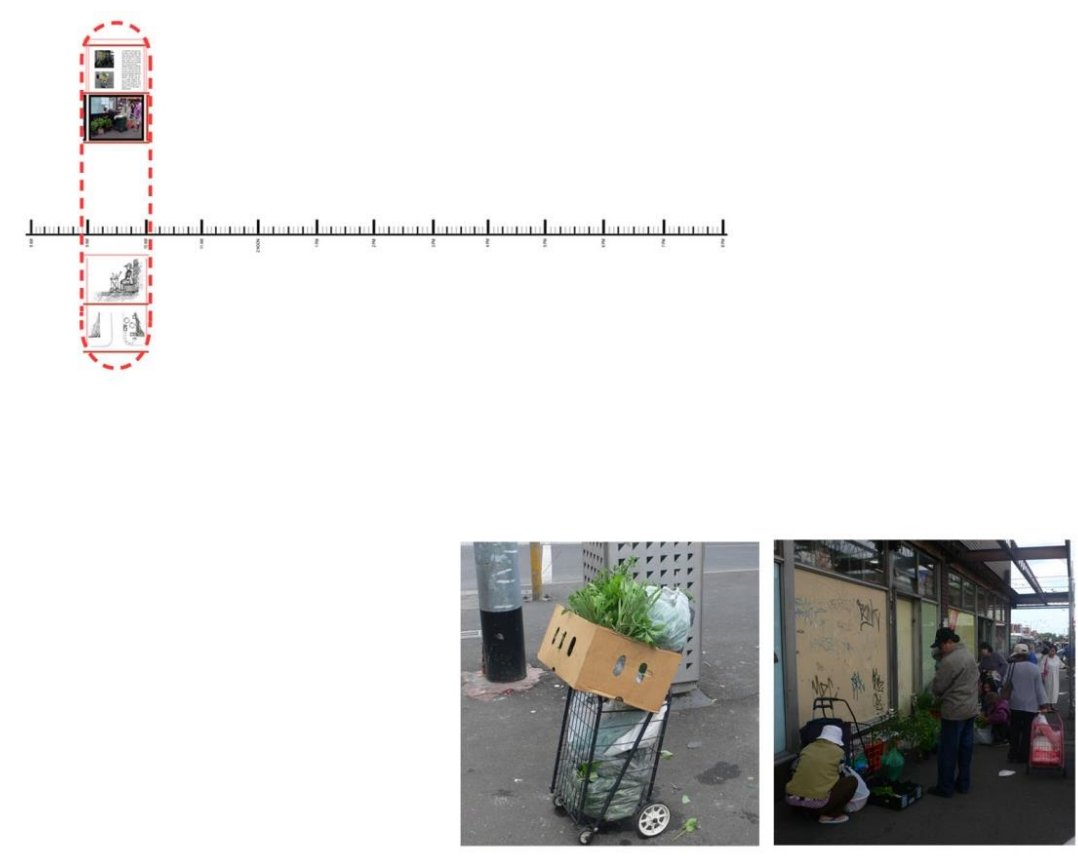

insights +

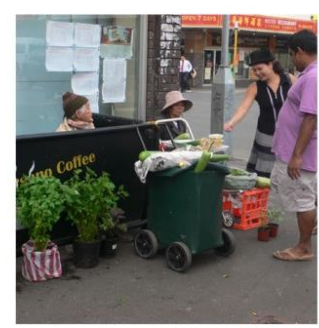

bodies $\hookrightarrow$ space

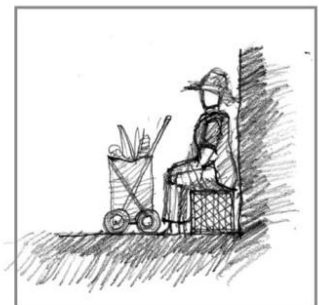

section

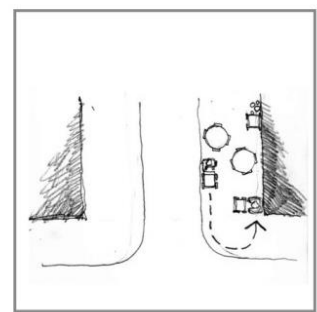

plan

self negotiation occupying threshold use of props proximate scale ig. 2: 


\section{self negotiation $\mathrm{PR} \quad$ threshold $\mathrm{SP}$ visual coverage $\mathrm{SP}$ \\ proximate scale $S C \quad$ convoluted boundaries $S P \quad$ rhythmic variation $P R$}

multiple social realities $\mathrm{PR}$ use of props $\mathrm{SP} S \mathrm{SC}$

This scheme was developed in a Master of Architecture studio at the University of Melbourne (2014). The project, a hotel for refugees in Melbourne, begins with the framing of the plight of asylum seekers in Australia on bridging visas. Close parallels can be drawn between the socio-economic conditions of the group the student highlights and the migrant groups in Footscray that are focused on in this study. Both are marginalised groups whose agency is not encouraged, and whose visual (and sensorial) display of difference is disconcerting to the larger public. The student writes: How might our cities of tomorrow extend hospitality to those truly seeking refuge (namely asylum seekers), without repatriation or a loss of cultural identity? $(\mathrm{Ng}, 2014)^{31}$

Economic empowerment and agency in space for the refugees had to be balanced against the need to placate a larger community who feel threatened by the visual presence of refugees especially in large numbers within the community, feeding into commonly held myths ( $\mathrm{Ng}, 2014) .{ }^{32}$ The hotel and its programme therefore take on a wholly tactical nature.

In order to gain access to the economic opportunities the city centre has to offer, the hotel is situated at the heart of Melbourne's Central Business District. The hotel is a habitable façade which appears nondescript. Within the façade there is accommodation and various other amenities for the refugees.

Programmatic requirements draw from tactical engagement with the surrounding urban environment, in particular a public car park. To gain insight into what is offered in terms of 'opportunity' here, the student reconceptualised the multimodal mapping methodology around the tactical typologies theorized by Ramirez-Lovering in Opportunistic Urbanism (Ramirez-Lovering, 2008). ${ }^{33}$ Mapping a 12 hour period of the car park she noted tactical actions that fell within the categories of 'appropriation' 'piggybacking' 'itinerant relationships' and 'open systems'. Mapping of site movements and patterns was also conducted.

Informal street vending, hairdressing, delivery services were identified as possible activities the inhabitants could engage in. Opportunities were also identified in underutilised infrastructure and the by-products of urban services. For example, hot air from the mechanical vents of neighbouring buildings was used to dry clothes and warm spaces. The hotel furniture as elements of the hotel façade is designed to be "detachable, operable or retrofitted opportunistically for trade" $(\mathrm{Ng}, 2014)^{34}$ - the use of movable props strengthening their tactical advantage. 1:1 prototypes were developed to interrogate embodied engagement with these elements.

The scheme presented here reflects many of the characteristics that were inherent to tactical action seen in the above mapping example. The convolution of boundaries between private hotel functions and public car park occurs as the occupants engage and occupy thresholds on either side. A self-negotiation of territories is promoted as the occupants infiltrate the urban surroundings, shifting agency into their own hands. Their informal trade activity creates a negotiated space of cultural identity. Engagement with environment and other bodies is at a proximate scale, and visually low-key, enhancing its tactical strength. Rhythmic variation - in this instance, counterpoint- to the existing rhythms allows very different (multiple) social realities to exist in the same space, unbeknownst to the wider population.

${ }^{31} \mathrm{Ng}$, A. (2014) Research proposal, Design Research, unpublished.

${ }^{32} \mathrm{Ng}$, A. (2014) Revised Research Question and Essay Outline, unpublished.

${ }^{33}$ Ramirez-Lovering, D. (Ed.) (2008) Opportunistic Urbanism, Melbourne: RMIT Publishing.

${ }^{34} \mathrm{Ng}$, A. (2014) Revised Research Question and Essay Outline, unpublished. 


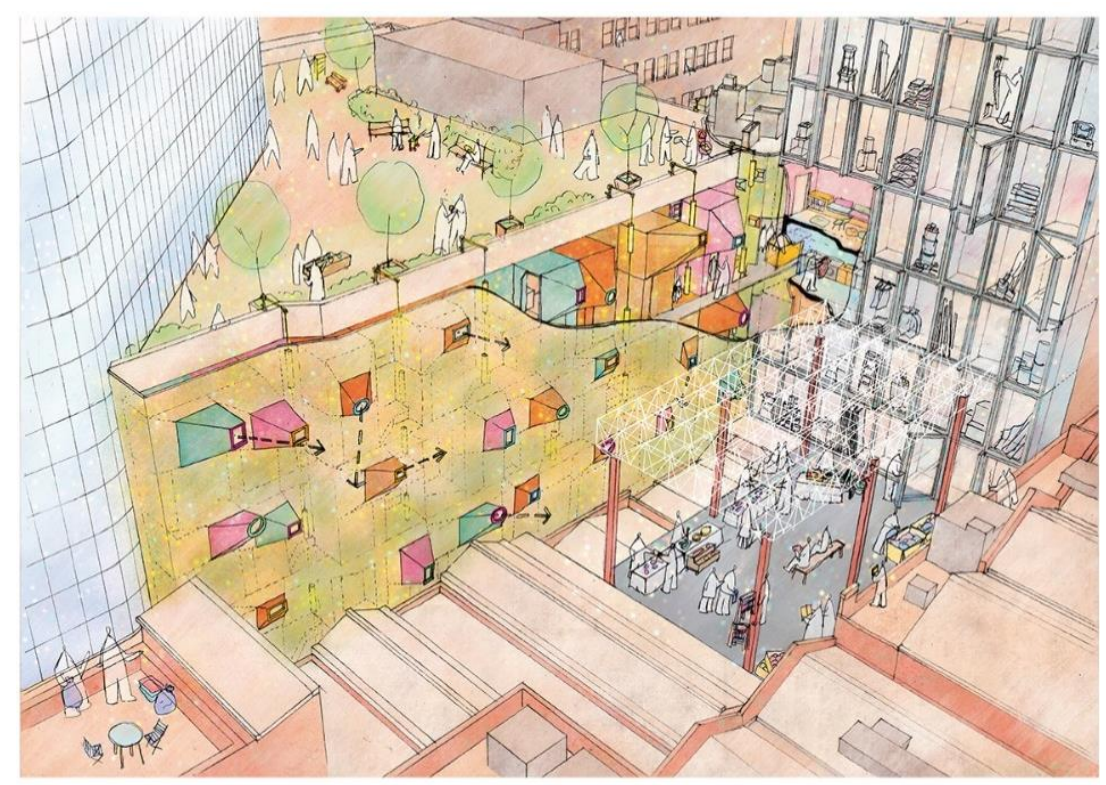

Fig. 3: Hotel for refugees consists of habitable facade where there is accommodation and other amenities. Source: Amelyn Ng

FURNITURE PROTOTYPE

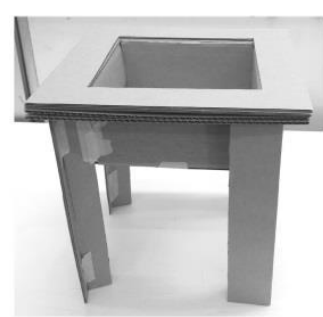

cardboard iteration of

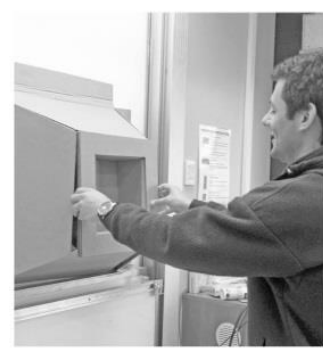

operability: hotel guest's discovery of seat

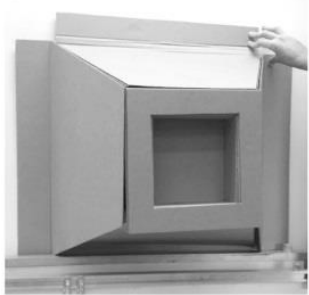

fitting seat into hotel room window projection

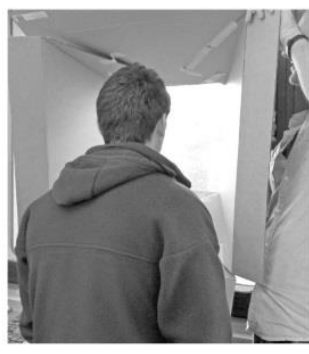

upon removal the guest has a clear view out

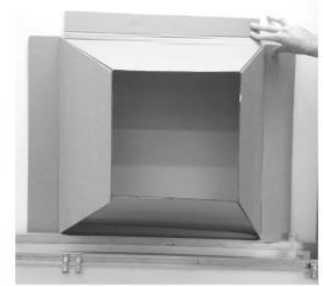

window projection opening

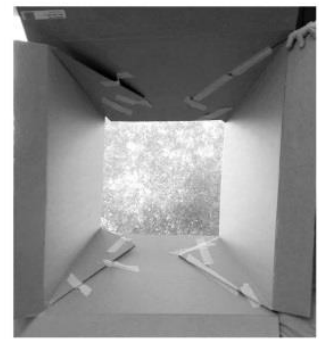

guest's 'picture view' out of hotel room

Fig. 4: Prototype research. 1:1 testing to assess relative heights, sizes and mobility. Source: Amelyn Ng 


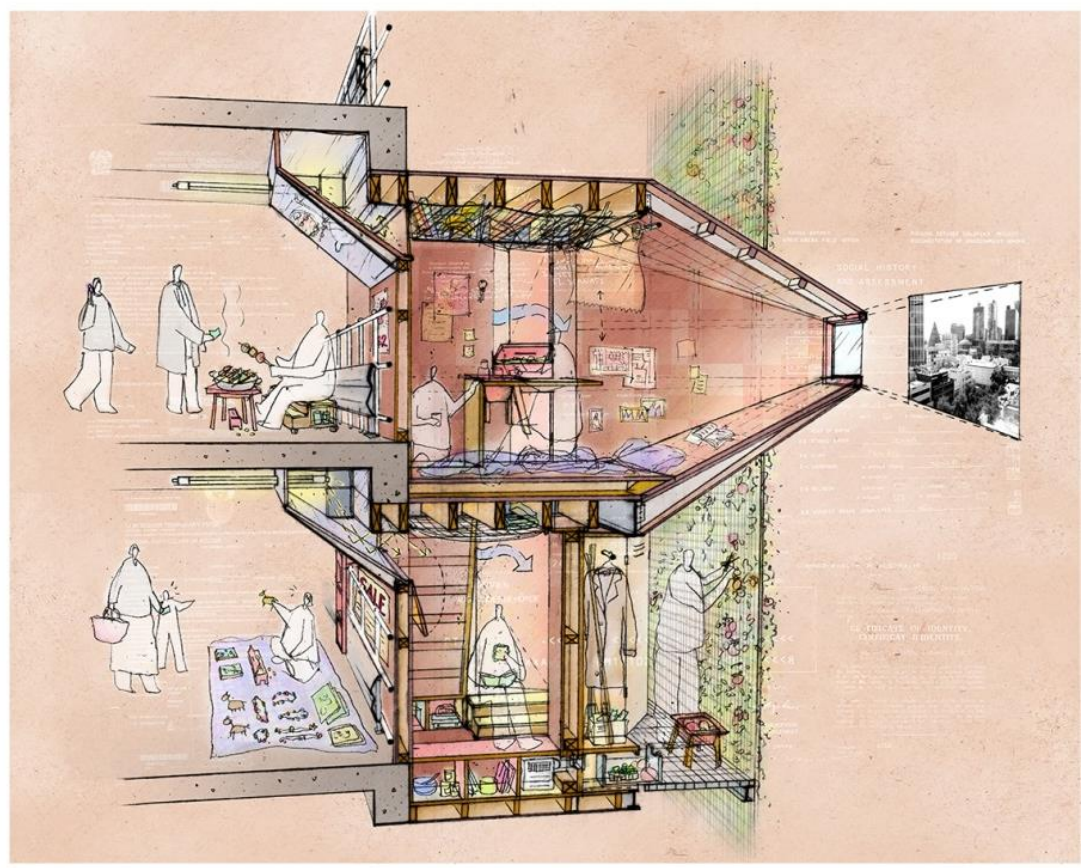

Fig. 5: Section of habitable facade.

Source: Amelyn Ng

\section{Conclusion}

The research presented in this paper attempts to highlight the sociality of the senses and looks specifically at the nuanced interplay between the physical, temporal, and social of everyday interactions to inform design. The particular episode from the multimodal mappings of Footscray presented in this paper revealed the significance of tactical occupation of space, allowing bodies that do not possess legitimate power to engage in the production of place or participate in culture (De Certeau, 1984). ${ }^{35}$ The above design demonstration reflected many of the socio-sensory markers that emerged in the mapping example. Both the mapping and the design demonstration illustrated how those occupying a marginal position in regeneration discourse and urban space because of disadvantaged backgrounds were afforded the opportunity to exercise creative autonomous action in the urban landscape, to their advantage.

The studio work demonstrated a collective leaning towards designs that were tactical in nature but also emphasised embodied engagement with the built environment impacting specific architectural parameters. As the schemes handled projects in areas earmarked for regeneration, they also demonstrated that it was possible for designers to engage with issues of social justice while designing for urban regeneration.

This research presents a particular way of reading urban conditions, specifically addressing the socio-sensory occupation of space and the body-space-time issues that result from this. It is not presented as an all-encompassing method or approach that addresses all the issues designers may face. It also generates knowledge of a particular scale - that of the body. This may result in overlooking some of the larger scale forces that work across a site. However, the methods presented here give insight into place making mechanisms and complexities unique to contexts that are contingent on specific epistemologies. It has the potential to inform professionals engaged in placemaking of alternative approaches that can help

${ }^{35}$ De Certeau, M. (1984) The Practice of Everyday Life, Berkley: University of California Press. 
produce regionally and culturally specific outcomes. I argued at the inception of the article that western methods of policy, planning and design may not be directly transferrable to other cultural contexts. Thoughtless application has often been detrimental to existing populations. Many south Asian societies are traditionally organised around kin-based social relationships. They are also still predominantly agrarian with many of the urban poor originally from rural contexts where boundaries are blurred, with fences and property not typically marked. How does this population with a specific concept of 'space', create place and impact urbanity? How could this knowledge inform design and planning decisions? As the methods presented here call for the acknowledgement of other ways of knowing and placemaking, further research could investigate the above questions in varying contexts. The resulting mappings can be contrasted to reveal specificities of placemaking.

This knowledge could inform the development of regional models of 'modernity' that are socially sustainable and specific to place. Ones that address inequity in the participation process, acknowledge the importance of existing spatial practices to inform design/planning decisions and provides a sense of continuity within the regeneration process.

\section{References:}

Adams, M. Moore, G. Cox, T. Croxford, B. Refaee, M. \& Sharples, S. (2007) 'The 24-hour City: Residents' Sensorial Experiences', Senses and Society, Vol 1, no. 2, pp. 201-216.

Careri F. (2002) Walkscapes: Walking as an Aesthetic Practice, Barcelona: Gustavo Gili.

Collins, P. (1990) Black Feminist Thought: Knowledge, Consciousness and the Politics of Empowerment, Boston: Unwin Hyman.

De Certeau, M. (1984) The Practice of Everyday Life, Berkley: University of California Press.

Degen, M. (2008) Sensing Cities: Regenerating Public life in Barcelona and Manchester, Abingdon: Routledge.

Eisenstein S. (1991) Towards a Theory of Montage: Sergei Eisenstein Selected Work Volume 2, Glenny, M. \& Taylor, R. (Eds.), London: British Film Institute Publishing.

Gehl, J. \& Svarre, B. (2013) How to Study Public Lif, Steenhard, K. (Trans.), Washington DC: Island Press.

Gehl, J. \& Gemzøe, L. (1996) Public Spaces, Public Life, Copenhagen: Danish Architectural Press.

Gehl, J. (1987) Life Between Buildings: Using Public Space, Jo Koch, J. (Trans.), New York: Van Nostrand Reinhold.

Goodwin, J. (1993) Eisenstein, Cinema and History, Urbana: University of Illinois Press.

Grosz, E. (1995) Space, Time and Perversion: Essays on the Politics of Bodies, Abingdon: Routledge.

Holl, S. (2000) Parallax, New York: Princeton Architectural Press.

Lynch, K. (1995) City Sense and City Design: Writings and Projects of Kevin Lynch, Banerjee, T. \& Southworth, M. (Eds.), Massachusetts: MIT Press.

Nesbitt, K. (Ed.) (1996) Theorizing a New Agenda for Architecture: An Anthology of Architectural Theory 1965-1995, New York: Princeton Architectural Press.

$\mathrm{Ng}$, A. (2014) Research proposal, Design Research, unpublished.

Ng, A. (2014) Revised Research Question and Essay Outline, unpublished.

Palipane, K. (2011) 'Towards a Sensory Production of Space: Developing a Conceptual Framework of Inquiry based on Socio-sensory Perception', in International Research Committee 21 (RC21) Conference - The Struggle to Belong: Dealing with Diversity in 21st Century Urban Settings, Amsterdam. www.rc21.org/conferences/amsterdam2011/edocs/Session\%201/RT1-1-Palipane.pdf

Pallasmaa, J. (2000) 'Hapticity and Time: Notes on Fragile Architecture,' in RIBA Discourse Lecture, EMAP Architecture. http://iris.nyit.edu/ rcody/Thesis/Readings/Pallasmaa\%20-\%20Hapticity\%20and\%20Time.pdf. 
Pallasmaa, J. (1996) 'The Geometry of Feeling: A Look at the Phenomenology of Architecture,' in Theorizing a New Agenda for Architecture An Anthology of Architectural Theory 1965-1995, Nesbitt, K. (Ed.)New York: Princeton Architectural Press. pp. 447-455.

Pardy, M. (2009) 'Multicultural Incarnations: Race, Class and Urban Renewal' in The Future of Sociology: Proceedings of the 2009 Annual Conference of The Australian Sociological Association, Canberra, ACT.

Parkes, D. \& Thrift, N. (1980) Times, Spaces and Places: A Chronogeographic Perspective, New York: John Wiley \& Sons Ltd.

Pink, S. (2008) 'An Urban Tour: The Sensory Sociality of Ethnographic Place-making', Ethnography, Vol. 9, no. 2, pp. 175-196.

Pink, S. (2009) Doing Sensory Ethnography, London: Sage Publications Ltd.

Profile.id, (2015) Footscray Birthplace, viewed 15 August, 2015, http://profile.id.com.au/maribyrnong/birthplace?WebID=110.

Ramirez-Lovering, D. (Ed.) (2008) Opportunistic Urbanism, Melbourne: RMIT Publishing.

Rapoport, A. (1976) The Mutual Interaction of People and their Built Environment: A Cross-cultural Perspective, The Hague: Mouton.

Rapoport, A. (1977) Human Aspects of Urban Form: Towards a Man-Environment Approach to Urban Form and Design, Oxford: Pergamon Press.

Rogerson, R. \& Rice, G. (2009) 'Making Sense of Places: 'Moral Geographies' of Sensory Urbanism', Architectural Theory Review, Vol. 14, no. 2, pp. 142-155.

Schon, D. (1985) The Design Studio: An Exploration of Its Traditions and Potentials, London: RIBA Publications for RIBA Building Industry Trust.

Sparkes, A. (2009) 'Ethnography and the Senses: Challenges and Possibilities', Qualitative Research in Sport and Exercise, Vol. 1, no.1, pp. 21-35.

Spivak, G. (1987) 'Can the Subaltern Speak?', in Marxism and the Interpretation of Culture, Cary Nelson C. \& Grossberg, L. (Eds.), Illinois: University of Illinois Press, pp. 67-111.

Thwaites, K. \& Simkins. I. (2007) Experiential Landscape: An Approach to People, Place and Space, Abingdon: Routledge. 